\title{
Resenhas
}

\section{A batalha pela alma política da Europa em tempos de crise}

Slavoj Zizek; Srecko Horvat. (2015). 0 que quer a Europa? Tradução de Miguel Serras Pereira. Lisboa, Relógio D’Água. 195p.

Há um adágio cunhado por Felipe González, um dos principais responsáveis pela repaginação da marcha comunitária europeia entre os anos 1980 e a década de 1990, que afirma ser a Europa concomitantemente um museu e um laboratório (González, 2010, p.129). A obra “O que quer a Europa?” retoma este último aspecto ao ter por fio condutor a reflexão sobre os variados desafios e eventuais alternativas à frente do processo de integração continental. Reunindo diversos artigos do pensador esloveno Slavoj Zizek e do filósofo croata Srecko Horvat, o livro conta ainda com prefácio do atual primeiro-ministro da Grécia Alexis Tsipras e com transcrições de uma entrevista e de um debate com os três personagens. As análises e as constatações dos referidos autores fornecem um poderoso diagnóstico das vicissitudes da Europa atual e propõem um ousado receituário para o futuro da União Europeia.

De fato, a preocupação com o estado da arte do processo europeu de integração faz sentido. A situação econômica do continente se mostrava a pior em várias décadas. Apenas considerando os casos mais emblemáticos (Irlanda, Portugal, Espanha, Grécia e Itália), é possível notar as dificuldades para a materialização de um viés constante de crescimento econômico - com picos recessivos superiores a 5\% do PIB em alguns períodos do quinquênio 2009-2014 ${ }^{1}$. No mesmo lapso temporal, todos os países mencionados mais a França, que detinham taxas de desemprego abaixo dos $10 \%$ da população economicamente ativa, passaram a apresentar tal indicador na casa dos dois dígitos ${ }^{2}$. Em tal contexto, as eleições diretas de 2014 para o Parlamento

\footnotetext{
${ }^{1}$ Disponível em: http://graphics.thomsonreuters.com/F/09/EUROZONE_REPORT2.html. Acesso em: 20 de abril de 2015.

${ }^{2}$ No caso da Grécia e da Espanha, tal índice foi acima dos 25\%. Disponível em: http:// graphics.thomsonreuters.com/F/09/EUROZONE_REPORT2.html. Acesso em: 20 de abril de 2015.
} 
Europeu mobilizaram apenas $42 \%$ do colégio eleitoral ${ }^{3}$, o menor resultado desde que o sufrágio popular foi adotado como método de escolha dos parlamentares do bloco em 1979. A baixa participação nas eleições da principal instância representativa da União Europeia (UE) evidencia um descrédito na roupagem institucional vigente e denota certa descrença acerca da capacidade da UE de aplacar os principais problemas da região.

"O que quer a Europa?" assume como ponto de partida esta indissociabilidade entre a crise econômica e os limites das instâncias de deliberação política da UE, explorando de que forma os solavancos dos mercados acentuam as mazelas da governança política do processo de integração. Com uma vertiginosa prosa, o texto trabalha inúmeros aspectos do momento delicado vivido pelo bloco, analisando os impactos da crise e de sua gestão nos âmbitos da imigração, dos direitos sociais, das respectivas identidades nacionais, da recepção da Turquia na UE, entre vários outros temas. Para tanto, a obra vale-se de referências que emulam a música clássica, cânones literários e até a cultura pop, além de um amplo repertório teórico que contempla de Max Horkheimer a Naomi Klein.

O pano de fundo da análise engendrada pelos autores é o reconhecimento do estágio avançado em que se encontra o processo de erosão do protagonismo europeu no cenário internacional (p.21). O esfacelamento da primazia e do prestígio do Velho Continente na senda global coloca em perspectiva certos traços identitários da própria organização social europeia - algo que a grave crise econômica em tela acentuou drasticamente. Assim ocorre no caso do questionamento sobre a viabilidade de manutenção do Welfare State, verdadeiro paradigma da relação entre o aparato estatal e a respectiva sociedade em boa parte da região ao longo do pós- $2^{\text {a }}$ Guerra Mundial. Ainda que seja necessário respeitar as diversas particularidades das experiências nacionais, fato é que o modelo da previdência social "é ou tornou-se parte fundamental daquilo que a Europa representa" (Giddens, 2007, p. 17).

A obra ora resenhada aponta para a existência de uma amplamente orquestrada tentativa de desmantelamento do Welfare State, abandonando uma tradição política de décadas em nome da "adaptação às regras da nova ordem mundial" (p.93). O mote da conexão entre o endividamento

\footnotetext{
${ }^{3}$ Disponível em: http:/ /www.europarl.europa.eu/elections2014-results/en/electionresults-2014.html. Acesso em: 20 de abril de 2015.
} 
dos Estados-membros e os gastos do modelo previdenciário europeu ensejou um cabedal de reformas envolvendo direitos trabalhistas e serviços públicos (Degryse; Jepsen; Pochet, 2013, p.37) - movimento aos auspícios da controversa trinca composta pelo Fundo Monetário Internacional, Banco Central Europeu e Comissão Europeia. O advento desta "Europa da austeridade" (p.159) repropõe a gramática política tanto das cenas nacionais quanto do próprio processo de integração, além de tencionar laços sociais já intensamente esgarçados pelo continente afora (p.41).

Em essência, é a esta disputa sobre a alma política do projeto de integração que "O que quer a Europa?" remete. A exploração de tal tema ocorre frente a um sintomático e incontornável caso de estudo: a crise na Grécia e seus desdobramentos. Como veremos abaixo, em vários momentos do texto a questão grega aparece como emblema da urgência de uma reinvenção política da União Europeia e como locus por excelência desta transformação. Trata-se de uma opção paradigmática já que possivelmente nenhuma outra sociedade do continente tenha sofrido mais do que a grega com os efeitos da referida débâcle econômica: queda do PIB em mais de $20 \%$ no período de cinco anos, maior taxa de desemprego do país em sete décadas e uma relação dívida/PIB superior a $170 \%$.

Ademais, há de se notar que as dimensões mitológicas da crise na Grécia foram intensificadas pela desastrosa condução das medidas de resgate pela já referida troik $a^{4}$. Os severos sacrifícios impostos à população pelo desmantelamento do Welfare State, aliados à ausência de melhora dos indicadores econômicos, colocaram em xeque de forma definitiva a governança tecnocrática tão característica do projeto integracionista europeu. Assim, surgiram as condições para o fortalecimento de iniciativas políticas de intensas tintas contestatórias (como o helênico Syriza e o espanhol Podemos), sobretudo face ao mote de que "a Europa será democrática e social ou deixará de ser Europa" (p.170).

Com textos anteriores à eleição do Syriza como sócio majoritário do governo grego (mas contemporâneos à escalada de popularidade da agremiação), a obra aponta que a possibilidade de resgate do bloco passa pela refundação das práticas políticas nacionais - iniciando-se pela grega

\footnotetext{
${ }^{4}$ Para uma mea culpa acerca do tema, vide INTERNATIONAL MONETARY FUND. Greece: Ex Post Evaluation of Exceptional Access under the 2010 stand-by arrangement. IMF Country Report n.13/156, 2013.
} 
(p.11 e p.14). De fato, há a necessidade de reformatar a relação entre o bloco e sua base social continental uma vez que é nítido o desaparecimento de um aspecto central da legitimidade dos projetos de integração: o compartilhamento de um fulcro ideológico-valorativo a orientar o avanço comunitário, ainda que seja um ideário restrito e de difícil verificação fática (Weiler, 2012, p.256). Para tal rejuvenescimento, seria imperioso um drástico descolamento da práxis política vigente: "só operando uma cisão sectária que rompa com o legado europeu estabelecido, só cortando-nos do cadáver em decomposição da velha Europa, podemos manter vivo um legado europeu renovado" (p.94).

Ainda que o trecho acima ecoe parcialmente a reflexão de Bauman (2006), fato é que os autores identificam este movimento exclusivamente com o redesenho das cenas políticas nacionais (p.111, 162-63). Esta postura não parece corroborar o advento de uma esfera pública continental, tradicional recurso da retórica europeísta. Defendida especialmente por Habermas $(2002,2012)$ a noção de uma esfera pública continental enfrenta diversos rechaços teóricos e fáticos (Carvalho, 2012, p.39-40). Seguindo uma linha de certa forma já explorada por Fraser $(1990,2007)$ sobre os escritos de Habermas, "O que quer a Europa?" afirma que a compreensão habermasiana não dialoga com o "problema real" do processo de integração (106): a desarticulação entre a atuação dos canais institucionais no patrocínio das ações de austeridade e o alheamento do corpo social - revelando o quanto é ficta a crença em uma Europa transnacional democrática uma vez que inexiste a dinâmica de aproximação, aclaramento e consenso pelo uso público da razão frente à inicial divergência de posicionamentos.

Aqui, contudo, reside a principal crítica à análise trazida por Zizek e Horvat já que há uma ausência de qualquer formulação sobre como se daria a proposta de superação da realidade vigente com a energização da cena política da integração por meio de experiências nacionais. Um mecanismo que talvez possa aclarar tal processo toma como pressuposto a progressiva europeização dos debates públicos nacionais. Abordagens empíricas demonstram que as agendas nacionais de fato incorporam cada vez mais temas da integração continental (Pereira, 2010). O fortalecimento de tal tendência não significa a inevitabilidade e a promoção daquela ampla esfera pública europeia, homogênea e voltada ao consenso - tão ao gosto habermasiano. Ao contrário, esta apropriação dos temas europeus pelas cenas nacionais cria um cenário de embates e conflitos vigorosos, que exige outro referencial teórico. 
Desta forma, há de se reconhecer que o traço definidor da política não é a busca pela concórdia, mas a manifestação da divergência (Rancière, 1996, p.368). A vitalidade de uma determinada experiência deliberativa é dada essencialmente pela presença da interlocução e do litígio: o dissenso corporifica a lógica organizativa da política. Tal reflexão tem ampla aderência à contemporaneidade do bloco europeu, sendo "possível pensar na autoridade política nacional como pavimento para a identidade continental, na medida em que a política pressupõe o alargamento da divergência" (Carvalho, 2012, p.41).

Ainda que o curto afastamento histórico não permita a confecção de uma análise mais elaborada, os desdobramentos da questão grega ao longo de 2015 parecem referendar esta análise. O tema teve repercussões próprias, reflexões peculiares e tratamentos específicos nas diversas cenas políticas dos Estados nacionais (sobretudo considerando as características de cada caso individual, vide Alemanha, Espanha, França, Itália, Portugal e, claro, Grécia) o que acabou influenciando decisivamente a atuação dos respectivos governos no plano regional e permitiu a ocorrência de um choque aberto de discursos e posições dos representantes de cada membro do bloco. Considerando os apontamentos do parágrafo anterior, vale notar que este embate aguerrido não implode os canais institucionais da UE e sim os fortalece - na medida em que a conversão do aparato burocrático em estrutura objeto de disputa aberta tem por requisito a assunção da possibilidade de apropriação, expressando reconhecimento e valorização. Esta parece ser a mais clara herança do tumultuoso período vivido recentemente pelos gregos e de seus correlatos efeitos em todo bloco.

Desta feita, as dificuldades atuais da governança da União Europeia e a luta pela alma política da Europa anteveem um horizonte de intensa experimentação na cena pública continental. Confirmando a mencionada alcunha de "laboratório" conferida por González à política do processo de integração, tal dinâmica consiste verdadeira condição de permanência e de relevância futura do bloco - além de, em um sentido mais amplo, ser um imperativo da reinvenção da própria democracia.

Daniel Campos de Carvalho*

\footnotetext{
* Daniel Campos de Carvalho é Professor Adjunto C da Universidade Federal de São Paulo (Unifesp) e Doutor e Mestre em Direito (área de concentração: Direito Internacional) pela Universidade de São Paulo (USP). E-mail: dccarva@uol.com.br; dccarvalho@unifesp.br .
} 


\section{Referências}

BAUMAN, Zygmunt.

(2006). Europa. Rio de Janeiro, Jorge Zahar.

CARVALH0, Daniel Campos de.

(2012). A pluralidade de sentidos da noção de esfera pública em face ao projeto europeu de integração comunitária e os desafios jurídicos correlatos. In: Fabia Fernandes Carvalho Veçoso (Org.); Direito Internacional em Contexto. São Paulo, Saraiva.

DEGRYSE, Christophe; JEPSEN, Maria; POCHET, Philippe.

(2013). The Euro crisis and its impact on national and European social policies. European Trade Union Institute Working Paper, n. 2013.5.

FRASER, Nancy.

(2007). Transnationalizing the Public Sphere: On the Legitimacy and Efficacy of Public Opinion in a Post-Westphalian World. Theory, Culture \& Society, v.24, n.4, p.7-30.

(1990). Rethinking the Public Sphere: A Contribution to the Critique of Actually Existing Democracy. Social Text, n.25-26, p. 56-80.

GIDDENS, Anthony.

(2007). A Europa na era global. Lisboa, Presença.

GONZÁLES, Felipe.

(2010). Mi idea de Europa. RBA, Barcelona.

HABERMAS, Jürgen.

(2013) Greece: Ex Post Evaluation of Exceptional Access under the 2010 stand-by arrangement. IMF Country Report, 13/156.
(2012). Um Ensaio sobre a Constituição da Europa. Lisboa, edições 70.

(2003). Mudança estrutural da esfera pública. Rio de Janeiro, Tempo Brasileiro.

(2002). A inclusão do outro. São Paulo, Edições Loyola.

INTERNATIONAL MONETARY FUND.

(2013) Greece: Ex Post Evaluation of Exceptional Access under the 2010 stand-by arrangement. IMF Country Report n.13/156

PEREIRA, Fabrícia Monteiro de Almeida.

(2010). A Europa nos Media - Estudo de caso sobre a Europeização da Esfera Pública Portuguesa. Dissertação de Mestrado em Ciência Política e Relações Internacionais Área de Especialização em Estudos Europeus - apresentada à Faculdade de Ciências Sociais e Humanas da Universidade Nova de Lisboa.

RANCIÈRE, Jacques.

(1996). 0 dissenso. In: Adauto Novaes (Org.); A crise da razão. São Paulo, Companhia das Letras.

WEILER, Joseph Halevi Horowitz.

(2012), Europe in Crisis - on "Political Messianism", "Legitimacy" and the "Rule of Law". Singapore Journal of Legal Studies. p. 248-268.

\section{Recebido em}

março de 2016

Aprovado em

março de 2017 